\title{
Article \\ Multivariate Regression Analysis of the NiTi Alloys' Surface Corrosion Depending on the Measured Oxygen Value: Tests in Three Different Marine Environments
}

\author{
Nataša Kovač ${ }^{1, *(\mathbb{C})}$, Špiro Ivošević ${ }^{2}\left(\mathbb{D}\right.$, Gyöngyi Vastag ${ }^{3}$, Peter Majerič ${ }^{4}(\mathbb{D})$ and Rebeka Rudolf ${ }^{4}(\mathbb{D})$ \\ 1 Faculty of Applied Sciences, University of Donja Gorica, Oktoih 1, 81000 Podgorica, Montenegro \\ 2 Faculty of Maritime Studies Kotor, University of Montenegro, Put I Bokeljske Brigade 44, \\ 85330 Kotor, Montenegro; spiroi@ucg.ac.me \\ 3 Faculty of Sciences, University of Novi Sad, Trg Dositeja Obradovića 3, 21000 Novi Sad, Serbia; \\ djendji.vastag@dh.uns.ac.rs \\ 4 Faculty of Mechanical Engineering, University of Maribor, Smetanova Ulica 17, 2000 Maribor, Slovenia; \\ peter.majeric@um.si (P.M.); rebeka.rudolf@um.si (R.R.) \\ * Correspondence: natasa.kovac@udg.edu.me
}

\section{check for}

updates

Citation: Kovač, N.; Ivošević, Š.; Vastag, G.; Majerič, P.; Rudolf, R. Multivariate Regression Analysis of the NiTi Alloys' Surface Corrosion Depending on the Measured Oxygen Value: Tests in Three Different Marine Environments. Crystals 2022, 12, 183. https://doi.org/10.3390/cryst 12020183

Academic Editors: Hongbin Bei, Sergio Brutti and Bolv Xiao

Received: 14 December 2021

Accepted: 23 January 2022

Published: 26 January 2022

Publisher's Note: MDPI stays neutral with regard to jurisdictional claims in published maps and institutional affiliations.

Copyright: (C) 2022 by the authors. Licensee MDPI, Basel, Switzerland. This article is an open access article distributed under the terms and conditions of the Creative Commons Attribution (CC BY) license (https:// creativecommons.org/licenses/by/ $4.0 /)$.

\begin{abstract}
Actual corrosion experiments are based mainly on methodologies that measure the corrosion rate of alloys as a function of the parameters that characterise different external influences and the specific environment in which the alloys are placed. Corrosive processes are viewed as complex stochastic processes described by linear and nonlinear probabilistic models. In contrast to these common ways of analysing corrosive processes, this paper investigates the corrosion process in terms of chemical changes in the alloys' surface compositions. For this purpose, two NiTi Shape Memory Alloys obtained by different technological production processes were tested, followed by an analysis of the empirical data obtained in a real experiment that included monitoring the corrosion behaviour. Both the analysed alloys were exposed to three different types of marine environment: air, tide, and sea. Data were collected continuously after 6,12 and 18 months of samples' exposure to the marine environmental influences. A total of six empirical databases were formed, one for each of the observed NiTi alloys in each of the three observed environments. The empirical databases systematised the data related to the measurements of the surface chemical composition obtained using Energy Dispersive X-ray (EDX) and Focused Ion Beam (FIB) analyses. Statistical analysis was performed to determine the correlation between the corrosion depth and the percentage of oxygen in the sample surfaces as well as to determine the similarities and differences in the corrosive behaviour of the two observed alloys in different marine environments.
\end{abstract}

Keywords: NiTi alloy; corrosion; EDX analysis; oxygen; multivariate linear regression; statistical analysis

\section{Introduction}

Over recent years, the use of smart materials, such as shape-memory materials, has attracted special attention from researchers. In that sense, numerous studies have been performed in laboratories and real conditions to facilitate the application of smart alloys in the maritime industry as well.

Since being discovered in 1932 [1], various families of alloys based on $\mathrm{Cu}, \mathrm{Al}, \mathrm{Ni}$, $\mathrm{Ti}$, and Fe have been used in different industries, such as medicine, transport, robotics, aviation, traffic, etc. [2-4]. Among the many different alloy families, NiTi alloys are the most attractive. William Buehler and Frederick Wang [5] recognised and described the shape memory effect on a nickel-titanium alloy (a NiTi alloy called nitinol) in 1962 [2,6].

Although the cost of NiTi alloys is high and they have very low fabrication, the main advantages of these alloys are in their application at temperatures from $-100{ }^{\circ} \mathrm{C}$ to $100{ }^{\circ} \mathrm{C}$, hysteresis up to $30^{\circ} \mathrm{C}$, and maximum recovery strain up to $8 \%$ [7]. In order to reach the better thermo-mechanical characteristics of the NiTi alloy, different production 
processes can be used such as: casting processes, vacuum induction melting, vacuum arc remelting, electron beam melting, plasma arc melting, and electron beam melting as the most commonly used processes [8].

During the corrosion process, metals are transformed into compounds that are most often found in nature. This process takes place as the result of the oxidation of metals and is reversed from the process of obtaining metals. During corrosion processes, the chemical composition of the material changes and the metal is decomposed completely or incompletely, or a layer of corrosion products is formed on its surface.

Due to the negative influence of the external, complex environmental factors in which metallic materials are usually used, there is a physical change in the metal that is normally detected as a decrease in the thickness and weight of the metal. External factors affect changes in the chemical structure of metals, which result in the occurrence of oxidation and a decrease in the percentage of less precious metals. By extending the time of exposure to negative environmental influences, corrosion processes intensify and changes in the physical form and chemical composition of the material become even more pronounced, manifesting as a reduction in volume and damage that destroys the material in depth.

Corrosion processes depend directly on the environment and operating conditions in which they are located and perform their functions. The more corrosive the environment and the more dynamic the processes, the faster the corrosion process will take place. In coastal and marine conditions, on the surface of the sea where the wet-dry cycles of seawater and atmosphere alternate, the effects of waves contribute to the acceleration of corrosive processes. Different chemical, physical, and biological parameters can accelerate the corrosion process in seawater and a coastal environment. Furthermore, humidity and air temperatures, wind and sea temperature, salinity, conductivity, and pressure are the most dominant influences that determine the course of corrosion processes [4].

Corrosion is an electrochemical process that occurs on metallic materials in different environments. As a consequence of the corrosion process, different types of corrosion can occur such as general, inter-granular, pitting, galvanic, crevice, stress, cavitation corrosion, etc. $[5,9]$. Each of these forms of the corrosion process takes place by the spatial separation of the anode and cathode sites, the presence of oxidants (dissolved oxygen and negative ions), and the salt concentration. In that sense, degradation on the surface of materials caused by electrochemical corrosion results primarily in the separation of anode oxidation processes of metals from cathode sites (the reduction of dissolved oxygen or other corrosive agents).

Due to the increase in the time of exposure to the environment, the corrosion rate for a longer period of time usually also increases and the weight of the metal decreases. In previous research, corrosion processes have been viewed mainly as linear models but also as nonlinear models, in which corrosive processes depend on various factors, in which the time of exposure to the environment prevails. A linear model was developed in Guedas, Soares, and Garbatov [10], while non-linear models are presented in Yamamoto and Ikegami [11], Paik et al. [12-14], Melchers [15,16], and in the studies of other researchers. As corrosive processes are very complex and are affected by many different factors and parameters of the environment in which the metal structures are located, some more modern corrosive models consider salinity, $\mathrm{pH}$, temperature and seawater flow, dissolved oxygen content, sulphur pollution, and fouling as model parameters [15,17].

In that sense, this research relies on an experiment in the real conditions of the marine environment. The paper analyses the influences of different types of marine environment (the atmosphere, tide, and sea) and the time of exposure on the changes in the chemical composition of two different NiTi alloy surfaces. In relation to the type of environment, the research investigates the dependence of the corrosion depth (expressed in $\mathrm{nm}$ of alloy wear) on the change in the percentage of oxygen in the alloy during 6,12, and 18 months of exposure. 


\section{Materials and Methods}

\subsection{Materials}

The production of NiTi alloys was based on the use of classical vacuum and continuous casting processes. The nickel (99.99 wt.\%) and titanium (99.99 wt.\%) were delivered by Zlatarna Celje d.o.o., Celje, Slovenia. Two different NiTi alloys were prepared in this research. NiTi (marked as NiTi1) as a cast alloy, was produced by classical casting at $\mathrm{T}=1500{ }^{\circ} \mathrm{C}$ and $p=10^{-3} \mathrm{mbar}$, resulting in the formation of an ingot with a diameter of $42.3 \mathrm{~mm}$. Another comparable NiTi alloy (marked as NiTi2) was produced by a combination of vacuum remelting at $\mathrm{T}=1500{ }^{\circ} \mathrm{C}$ and $p=10^{-3}$ mbar and the continuous casting methodas described in previous reports $[18,19]$, resulting in the formation of a rod. In total, nine NiTi1 disk samples with a thickness of $3.4 \mathrm{~mm}$ (Figure 1a), and nine NiTi2 rodshaped samples with a diameter of $11.9 \mathrm{~mm}$ and a length of $50 \mathrm{~mm}$ (Figure 1b) were cut by electro-erosion. Each type of sample had a special shape (hole, notch) and in this way, it was possible to perform tests due to the attachment of the carrying rope. The samples were then mounted in a hot-mounting mass and ground with abrasive paper in grades of 180-4000 on the grinding/polishing machine BUEHLER Automet 250 and EcoMet 250 (Leinfelden-Echterdingen, Germany). A napless cloth and $1 \mu \mathrm{m}$ polishing suspension were used for polishing the samples. After polishing, the samples were cleaned by ultrasound. This was followed by chemical etching of the polished surface with a solution composed of $3 \mathrm{~mL} \mathrm{HF}, 6 \mathrm{~mL} \mathrm{HNO}_{3}$, and $100 \mathrm{~mL} \mathrm{H}_{2}$ for NiTi1 105 s, and NiTi2 120 s. The revealed chemically-etched microstructures were observed with a Nikon EPIPHOT 300 light microscope (Nikon, Japan) and the characteristic microstructures are shown in Figure 1c,d. Both microstructures are typically dendritic, with primary and secondary dendritic areas. The difference in microstructure is that it is more oriented in the rod samples made by continuous solidification, in accordance with the technology of continuous casting, where the formation of the microstructure is most influenced by the cooling rate and other conditions of solidification.

Three samples of each NiTi alloy were located in the atmosphere (close to the coast and three metres above the tide line), three samples were located in the tidal zone, and the remaining three samples were placed in the sea (at a depth of three metres). This way of arranging the samples guaranteed that the alloy pieces stayed alone in one zone and the corrosion of NiTi alloy in the tidal zone and full immersion zone occurred separately. The tidal zone is a splash zone as well and in that zone, samples were exposed to the atmosphere, sea, and waves due to daily changes. More precisely, two sets of samples were exposed to a fixed environment (only the atmosphere or only seawater) and the third set of samples was exposed to a dynamic, changeable environment (the periodic influence of the atmosphere and seawater). In the tidal/splash zone, the difference between tide and ebb is above $300 \mathrm{~mm}$ per day and the samples were $120 \mathrm{~mm}$ long. These dimensions of the samples were used to ensure that the conditions in which the samples were situated would change twice during each day (the influence of tide and ebb) and to ensure a constant influence of the waves. A conceptual research model that follows the research methodology from this paper is presented in Figure 2. In our previous article [20], a similar methodology was used in the case of a CuAlNi alloy. While conducting the experiment between August 2019 and March 2020, the parameters of the seawater salinity were measured under the "Coastal Sea Ecosystem Monitoring Program of Montenegro", at the Institute of Biology, University of Montenegro. Different values of seawater salinity were measured on the sea's surface in the tidal zone and at a depth of $3 \mathrm{~m}$ where the samples were located. On the sea's surface during 2019, the minimum value of salinity was measured at 14.0 (\%o) (December), the maximum value was 39.00 (\%) (September), while the average value was $30.33(\%)$. In the sea at a depth of $3 \mathrm{~m}$, the minimum value of salinity was measured at $27.6(\%$ ) (December), the maximum value was 39.40 (\%o) (August), while the average value was $36.68(\%$ ). 


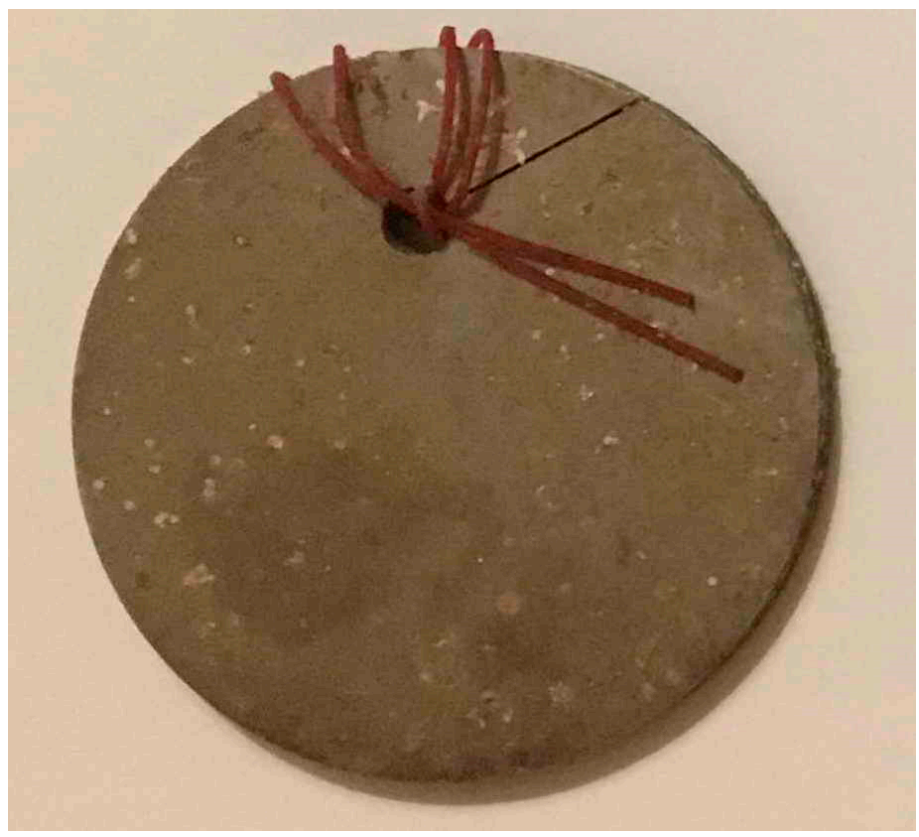

(a)

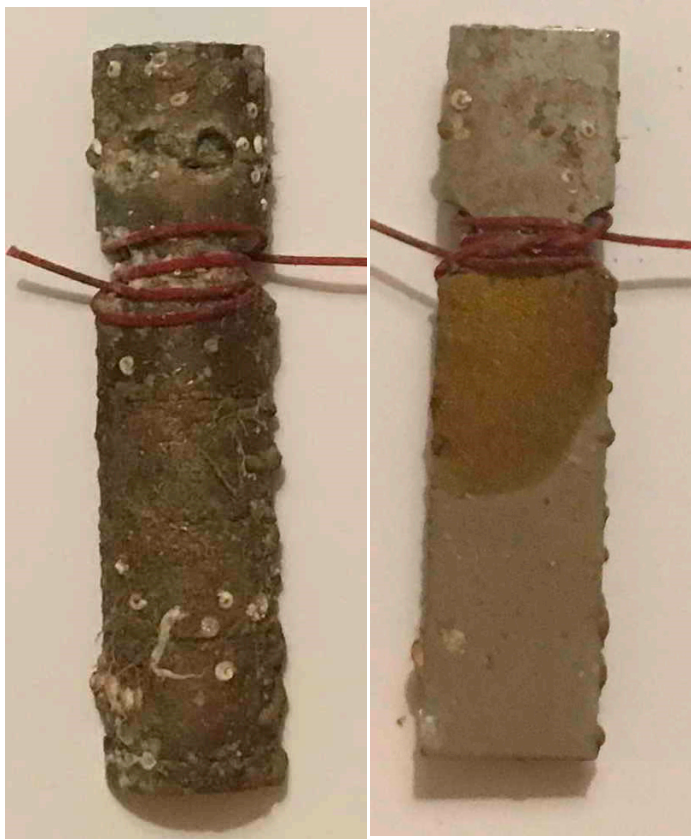

(b)

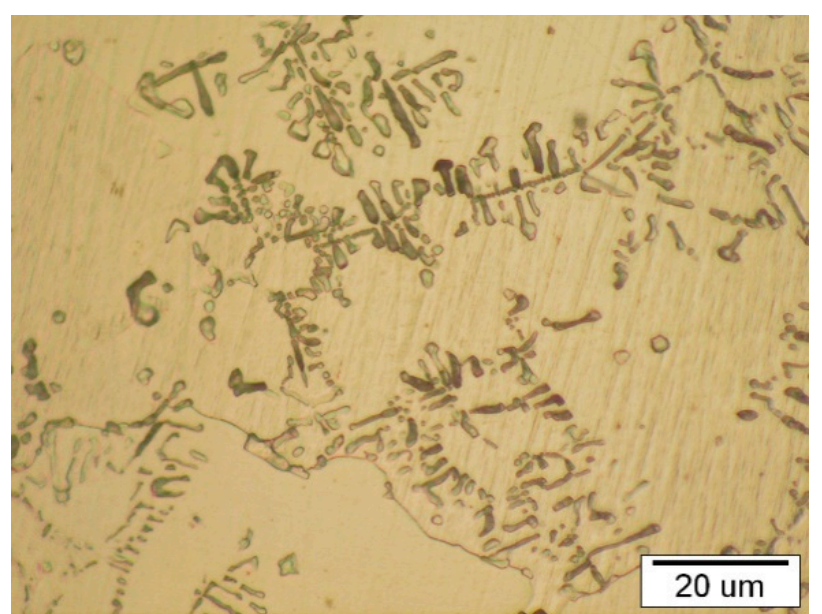

(c)

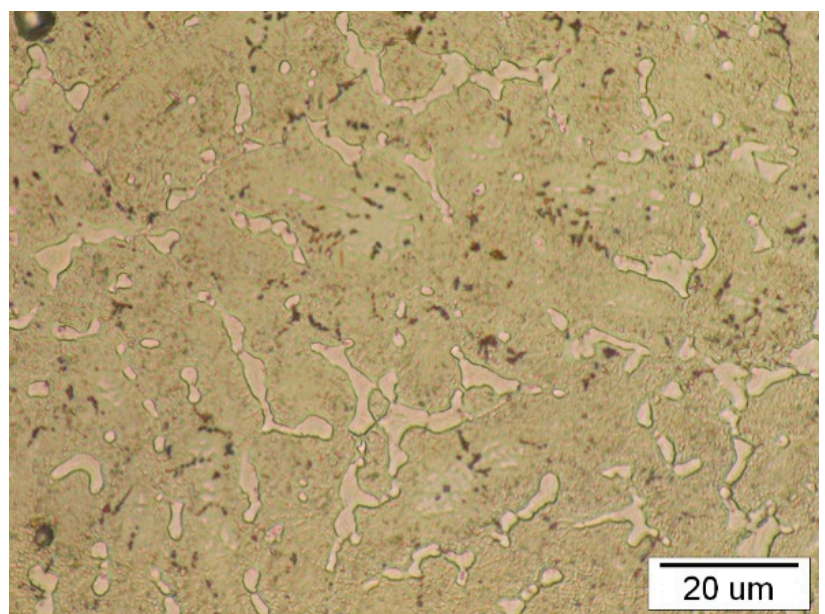

(d)

Figure 1. A sample of the NiTi1 alloy disk (a), NiTi2 rod alloy (b), the optical microstructure of the NiTi1 alloy (c), and NiTi2 alloy (d).

Metallographic observations and microstructure observations of all NiTi1 [21] and NiTi2 samples were conducted in order to monitor the occurrence of the corrosion process and prepare the samples for testing [22]

To determine the changes in the chemical composition of the surfaces that had been exposed to different environments, before the start of the experiment, preliminary analyses were performed using Inductively Coupled Plasma (ICP) and X-ray Fluorescence (XRF). The measured elements (such as chemical composition) are shown in Table 1 [22].

\subsection{Methods}

Because different environments have different effects on the corrosion process, this experiment is based on the study of three different environmental influences on the considered NiTi alloys. The two considered environments are static and represent the atmosphere and the sea. The third marine environment, the tide, is dynamic because it is characterised by changes in the sea's surface, where wet and dry sea cycles alternate during the day. The 
experiment consisted of examining the behaviour of alloys in three different environments for a total of 18 months. Specifically, three samples of NiTi1 and NiTi2 alloys were analysed after 6 months, 12 months, and 18 months of exposure to each test environment.

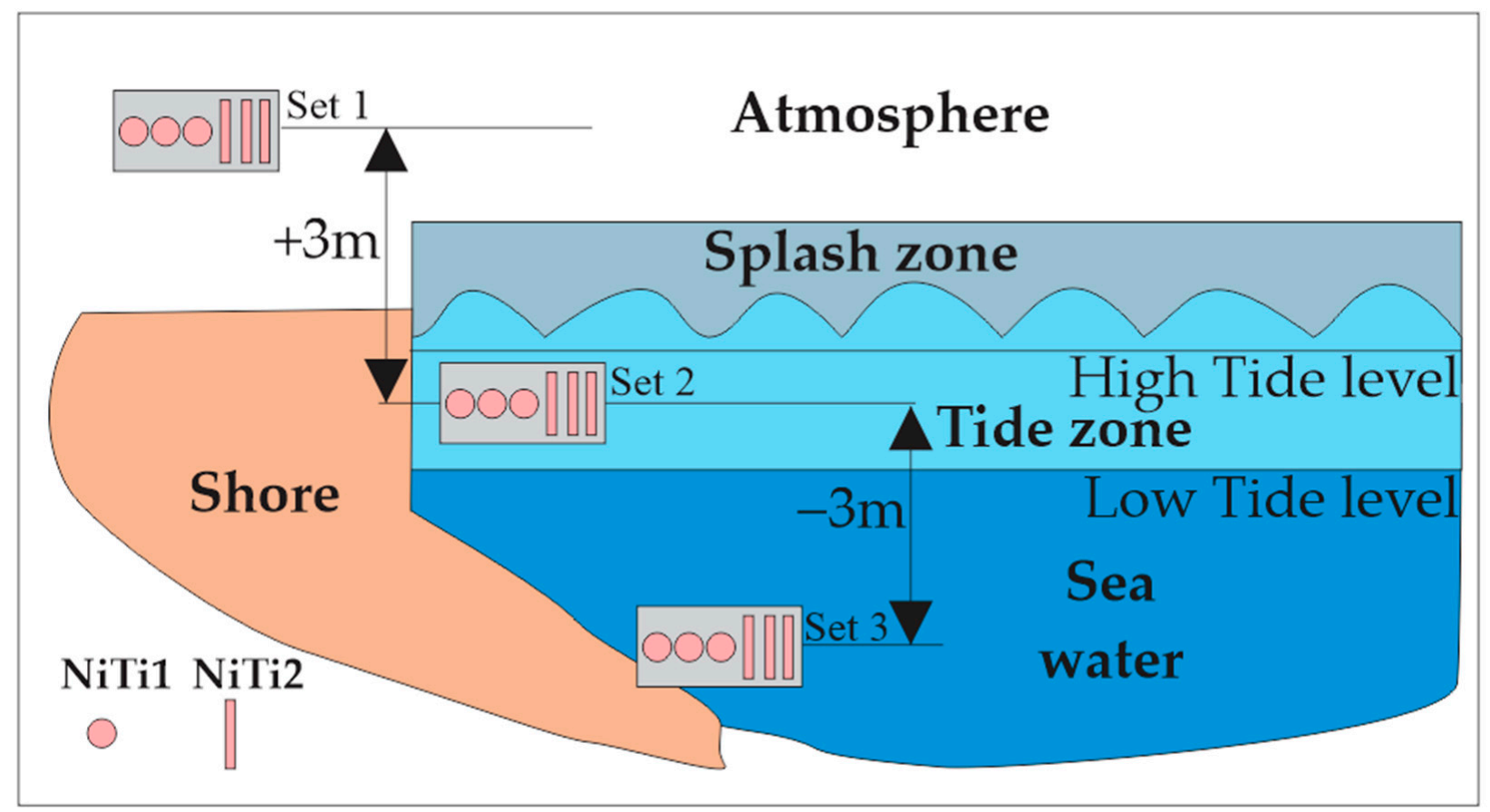

Figure 2. Graphical representation of the NiTi alloys' conceptual research model.

Table 1. Chemical composition of the NiTi1 and NiTi2 samples.

\begin{tabular}{ccccccc}
\hline Sample & \multicolumn{2}{c}{$\%$ Ni } & \multicolumn{2}{c}{$\%$ Ti } & \multicolumn{2}{c}{$\%$ Fe } \\
\hline & ICP & XRF & ICP & XRF & ICP & XRF \\
\hline NiTi1 & 55.4 & $55.2-55.5$ & 44.6 & $44.4-44.8$ & $/$ & $/$ \\
NiTi2 & 62.6 & $62.5-62.6$ & 35.9 & 35.9 & 1.4 & 1.4 \\
\hline
\end{tabular}

The samples were monitored and measured, with the aim of determining the depth of corrosion in $\mathrm{nm}$, as well as with the aim of monitoring the chemical composition, i.e., the percentage of oxygen on the surface of the alloy. To obtain the depth of corrosion and the chemical composition of the alloys' surfaces, two methods were used to measure the mentioned data related to the corrosive processes.

\subsubsection{Data Collection Methods}

As we have already pointed out, the data related to the depth of corrosion of NiTi alloys as well as the percentage of formed oxygen in the metal structures, caused by the development of corrosive processes, are of fundamental importance for this article. These requirements led to the selection of two adequate methodologies applied in the data collection phase with the aim of forming empirical databases for the corrosive processes of NiTi1 and NiTi2 alloys.

Characterisation of the NiTi alloys' surface was performed with the Focused Ion Beam (FIB) method on an environmental Scanning Electron Microscope Quanta 3D (FEI, USA) for measuring the depth of corrosion [23]. A focused beam consists of primary gallium ions, where the diameter of the ion beam is very small (e.g., $6 \mathrm{~nm}$ at a current of $1 \mathrm{pA}$ ), which, due to the high density of the ions, allows for a good contrast image. In this way, it is possible to etch the surface of the sample, followed by cutting, polishing the cut surface, etc. The ion gun on the Quanta microscope allows not only SEM observation of the surface but also 
the surface treatment and analysis of the microstructure below the surface. Based on that, the FIB method was used to determine the depth of corrosion (in $\mathrm{nm}$ ) on the surface, and to scan the area below the surface of the NiTi1 and NiTi2 alloys after 6, 12 and 18 months of exposure to each of the three observed seawater environments.

Figure $3 a, b$ shows the corresponding FIB images (with adequate magnifications) as well as the corrosion depths (expressed in $\mathrm{nm}$ ) for the NiTi1 and NiTi2 samples exposed to the sea for 18 months. All experimental values of corrosion depth used for further analysis were obtained in the same way. Measurements were collected systematically for each observed sample after 6, 12, and 18 months of exposure to one of the three observed environments.

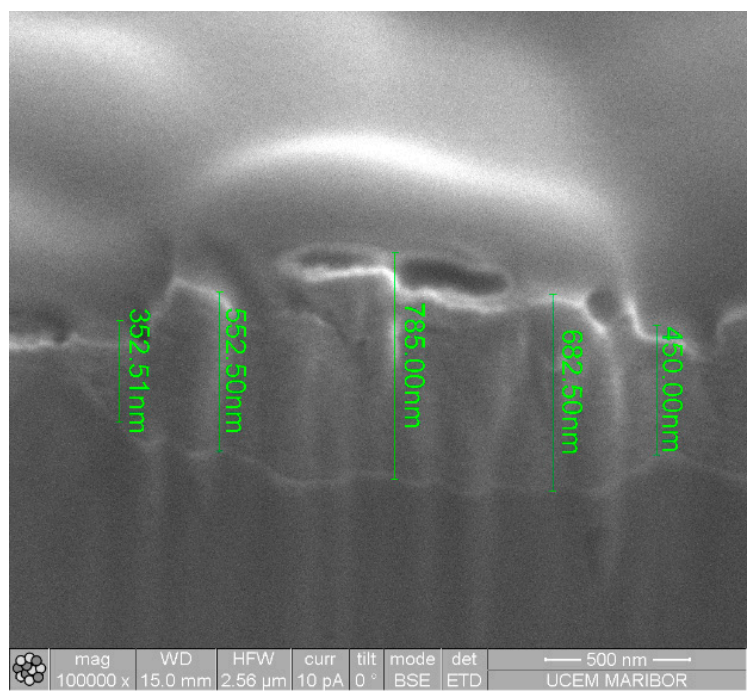

(a)

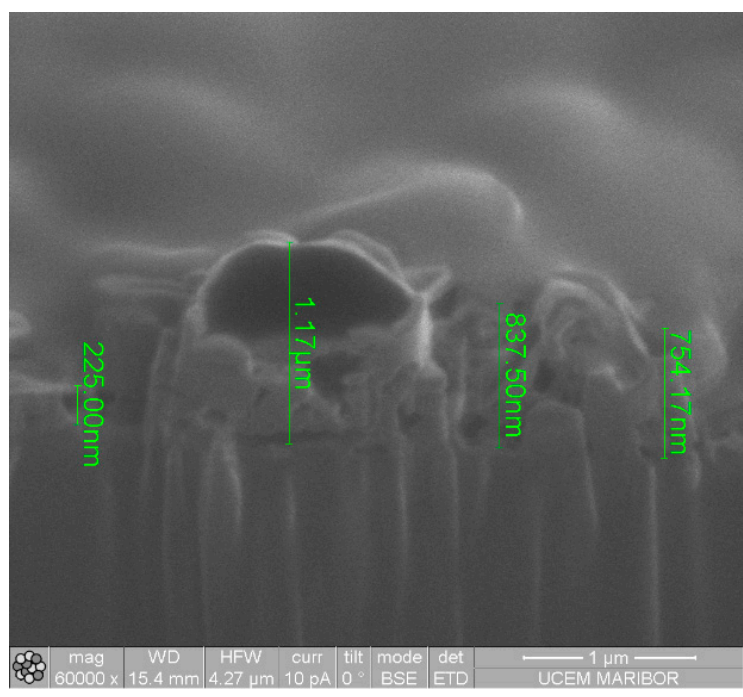

(b)

Figure 3. FIB measurement value of the corrosion layer in $\mathrm{nm}$ on the NiTi-1 sample 18 month in the sea (with 100,000 magnification) (a) and measurement value of the corrosion layer in $\mathrm{nm}$ on the NiTi-2 sample 18 months in the sea (with 60,000 magnification) (b).

The chemical composition of the observed NiTi1 and NiTi2 alloy surfaces were determined using a high-resolution Field Emission SEM Sirion 400 NC (FEI, Hillsboro, OR, USA). The microscope was equipped with an Energy Dispersive Spectrometer (EDS)-Oxford INCA 350 for micro-chemical analysis (Oxford instruments, Abingdon, UK) [24]. The EDX semiquantitative analysis provided data related to the chemical composition of the NiTi alloy surfaces after corrosion as well as the oxygen content formed on the surface of the tested samples which is considered as the input parameter of the future corrosion model.

\subsubsection{Multivariate Linear Regression}

Linear regression is one of the common statistical tools that can build a predictive model based on empirical databases. There are two basic types of linear regression. Simple linear regression is related to a model that has only one independent variable, while multivariate linear regression corresponds with a model that is built from several independent variables [25].

If a dependent variable is labelled with $Y$, while $X$ represents the vector of independent variables of dimension $N+1$, then a linear regression model can be represented in the following way:

$$
Y=\beta_{0}+\beta_{1} x_{1}+\beta_{2} x_{2}+\cdots+\beta_{N} x_{N}
$$

The common term for $Y$ is "response variable", while $X$ is known as the "predictor" [26]. The coefficient $\beta_{0}$ represents a fixed value of a model, i.e., an expected mean value of $Y$ when $X=0$, and it is known as an intercept. Coefficient values $\beta_{0}, \beta_{1}, \beta_{2}, \ldots, \beta_{N}$ are unknown and should be estimated in a way that best describes the linear dependence of 
$Y$ on $X$. Once the model's parameters are determined, the model can be used further to predict the value of $Y$ for a given value of the vector $X$.

Preliminary research has shown that simple linear regression does not provide adequate precision if used as a tool to predict the corrosion depth of NiTi alloys. Given the complexity of the corrosive processes, especially when samples are exposed to the marine environment, it becomes clear that it is necessary to observe several factors that affect the development of corrosion on the surface of alloys simultaneously. Therefore, the research presented in this paper is based on the application of multivariate linear regression to characterise the depth of corrosive damage to the observed samples of NiTi1 and NiTi2 alloys. The depth of corrosion is observed as a function of the exposure time of the observed marine environment influence and the measured amount of formed oxygen on metal structures caused by the development of corrosive processes. More precisely, in the statistical analysis, the data detected by EDX measurements of the chemical structure for NiTi1 and NiTi2 alloys were paired with the data of their FIB measurements related to the corrosion depth development on the samples' surfaces. This methodological approach allowed the corrosion depth to be considered as a dependent variable in the regression analysis, while the predictor variables were the exposure time of the seawater environment influence and the amount of oxygen formed on the samples' surfaces.

\section{Results}

Statistical analysis was performed with the aim of establishing the dependence between the corrosion depth of the NiTi1 and NiTi2 alloys and the observed percentage of oxygen formed on the surfaces of the metal samples. Multivariate linear regression was used as a tool to build a statistical model that will predict the corrosion depth of the NiTi1 and NiTi2 alloys (measured in $\mathrm{nm}$ ) accurately in three types of the marine environment as a function of the environmental exposure time and oxygen percentage formed on the surfaces of the samples. Oxygen amounts expressed as a percentage, together with the exposure time expressed in months were considered explanatory variables in each of the six formed regression models, while the corrosion depth played the role of the response variable.

The basic descriptive statistics, i.e., Mean, Standard Deviation (StD), minimum (Min), first quartile (Q1), median, third quartile (Q3), and maximum (Max), related to the formed empirical database for the NiTi1 samples are shown in Table 2. Table 2 shows the number of measured points on the samples $(n)$, the basic statistical values related to the percentage of oxygen, and the corresponding corrosion depth (expressed in $\mathrm{nm}$ ) statistical values observed on the NiTi1 alloy for each considered environment. Table 3 has an identical structure but shows the descriptive statistics of the formed empirical databases for NiTi2 alloy corrosive processes.

Table 2. The descriptive statistics of input data related to the NiTi1 alloy.

\begin{tabular}{ccccccccccc}
\hline Environment & Variable & $\boldsymbol{n}$ & Mean & StD & Min & Q1 & Median & Q3 & Max \\
air & oxygen & 31 & 11.41 & 10.15 & 0.00 & 2.02 & 8.28 & 19.34 & 30.00 \\
& corr. depth & 31 & 43.36 & 8.84 & 30.00 & 37.50 & 40.00 & 50.00 & 58.33 \\
\hline \multirow{2}{*}{ tide } & oxygen & 41 & 29.90 & 8.68 & 9.14 & 24.77 & 28.57 & 35.61 & 48.41 \\
& corr. depth & 41 & 38.78 & 10.86 & 22.50 & 30.00 & 37.50 & 45.83 & 66.67 \\
\hline \multirow{2}{*}{ sea } & oxygen & 49 & 26.67 & 13.16 & 0.00 & 15.04 & 29.82 & 37.63 & 52.48 \\
& corr. depth & 49 & 281.3 & 158.5 & 41.7 & 168.8 & 308.3 & 414.6 & 575.0 \\
\hline
\end{tabular}

The Mean values of the measured oxygen concentration for the NiTi1 alloy show that the lowest percentage of developed oxygen was in the case of air environments, while approximately the same percentage of oxygen was present on the alloy surface in both the tidal and sea environments. The scattering of the percentage of oxygen was approximately the same in the air and sea environments while slightly less in the tidal environment. The developed corrosive processes had similar values in the air and tidal environments, while 
in the marine environment there was a significantly higher value of the measured depth of corrosion. The scatter values of corrosion depth were similar for air and tide, but the values for the sea environment were significantly higher.

Table 3. The descriptive statistics of input data related to the NiTi2 alloy.

\begin{tabular}{ccccccccccc}
\hline Environment & Variable & $\boldsymbol{n}$ & Mean & StD & Min & Q1 & Median & Q3 & Max \\
air & oxygen & 84 & 19.73 & 7.812 & 4.110 & 15.60 & 20.63 & 23.80 & 38.97 \\
& corr. depth & 84 & 54.89 & 15.44 & 29.17 & 45.21 & 55.00 & 62.50 & 95.83 \\
\hline \multirow{2}{*}{ tide } & oxygen & 71 & 41.05 & 26.80 & 5.00 & 16.92 & 38.26 & 56.80 & 141.67 \\
& corr. depth & 71 & 156.5 & 147.1 & 37.5 & 47.5 & 72.5 & 258.3 & 708.3 \\
\hline \multirow{2}{*}{ sea } & oxygen & 64 & 57.52 & 41.28 & 0.00 & 30.86 & 42.09 & 72.08 & 171.7 \\
& corr. depth & 64 & 286.2 & 202.7 & 70.8 & 139.4 & 215.8 & 376.0 & 858.3 \\
\hline
\end{tabular}

From Table 3, in the case of the NiTi2 alloy, it can be seen that the average values of the percentage of oxygen were the lowest for the air and that they showed growth when the tidal and sea environments were observed. The increasing trend of the measured corrosion depth average value was the same; it was the smallest for the air and then increased in the tidal and sea environments, but the average depth of corrosion was three times higher in the tidal environment, and five times higher in the marine environment. The values of the Standard Deviation followed these growth trends from the air environment and tidal environment to the highest values for the sea environment, both from the point of view of the observed oxygen values and the observed corrosion depth values. The largest scatter values were observed for the depth of corrosion in the tidal environment and the sea environment.

When comparing the mean oxygen percentage of the two alloys, it was noticed that the measured values for the NiTi2 alloy were higher in all three environments than the measured values of oxygen for the NiTi1 alloy. Compared to the detected mean corrosion depth, NiTi1 and NiTi2 alloys showed similar properties in the air and sea environments but differed significantly in the tidal environment. The average value of the corrosion depth was four times higher for the NiTi2 alloy compared to the NiTi1 alloy for the tidal environment. The variations in the values of the average percentage of oxygen, as well as the average measured depth of corrosion in the air environment, were similar for both alloys, but differences were observed for the tidal environment as well as the sea environment. In both environments and for both measured Mean values of the observed values, the NiTi2 alloy showed significantly higher scatter values.

Figure 4 shows the dependence of the corrosion depth of the NiTi1 and NiTi2 alloys on oxygen percentage and the time of exposure to the environment influence graphically. More precisely, Figure 4 visualises the empirical databases formed for the alloys NiTi1 and NiTi2. The data, as well as the belonging graphical representations, are grouped with respect to the three types of marine environment. The corrosion depth values are shown on a colour scale, whereby the lowest values are blue, while the highest values are shown in red. In all images, the corrosion rate is shown as a function of two independent variables (oxygen percentage and exposure time expressed in months) that are the basis for the following regression models.

Figure 5 shows the results of a correlation analysis between the corrosion depth and independent variables. The correlation analysis is presented in the form of a correlation matrix for both observed alloys in each of the three seawater environments. Pearson's correlation coefficient [27] is used in this paper as one of the most common correlation coefficients.

According to Figure 5a-f, in the three types of the environment examined and for both alloys, only positive correlation effects occurred. In the correlation matrices shown in Figure 5, the degrees of correlation are further highlighted by the intensity of the blue colour assigned to each cell of the matrix. As expected, both alloys showed tendencies to increase the depth of corrosion in all observed types of the marine environment (air, tide, 
sea), when taking into account the increase in the duration of exposure of the alloy to the environment and the percentage of oxygen formed.

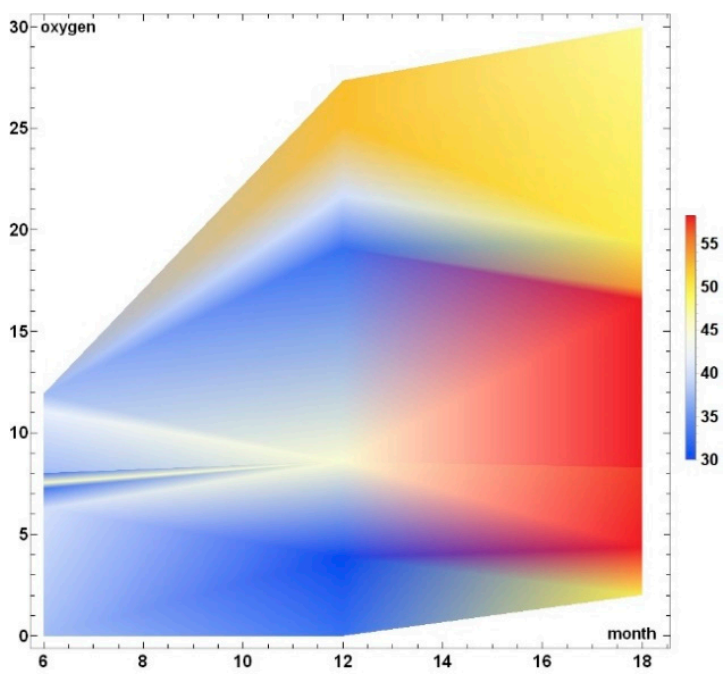

(a)

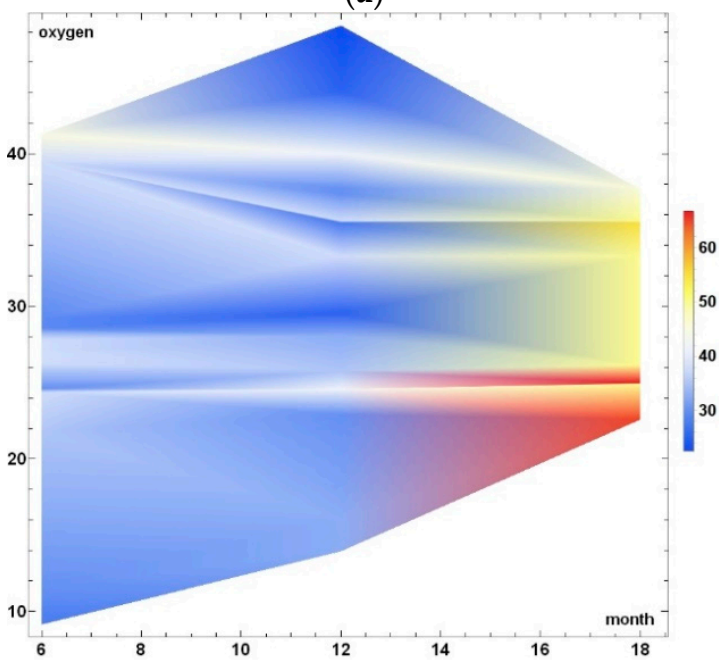

(c)

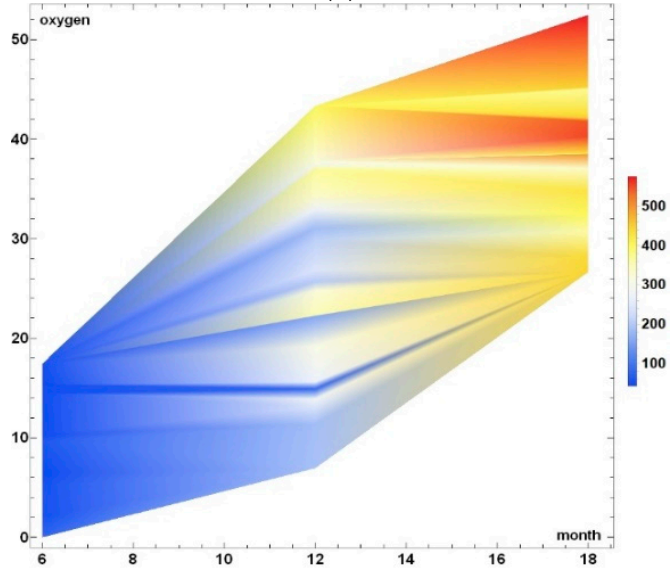

(e)

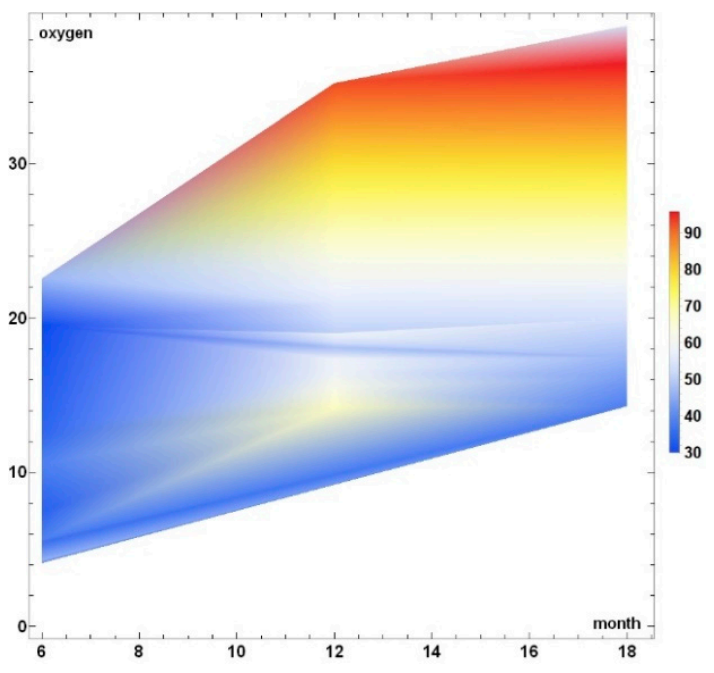

(b)

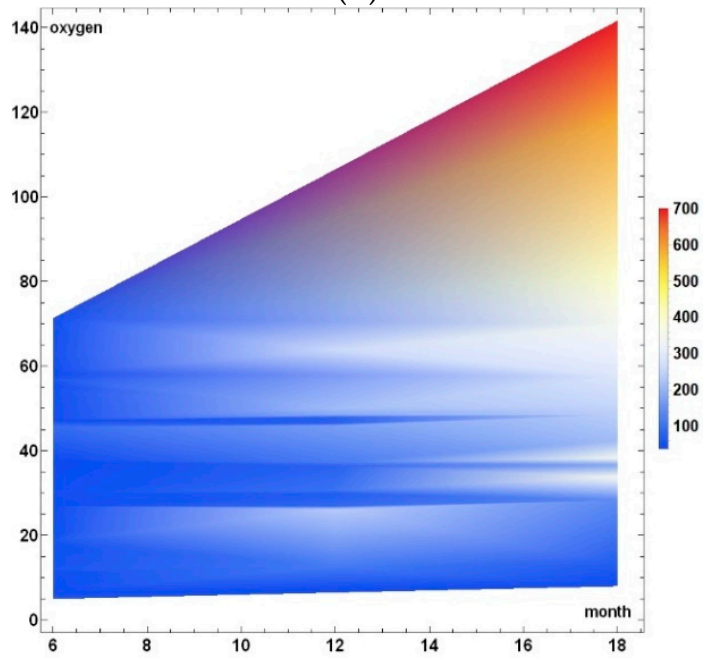

(d)

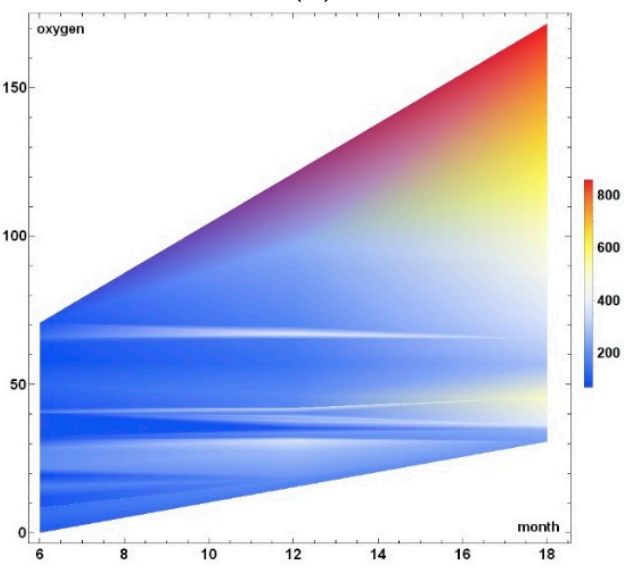

(f)

Figure 4. Empirical corrosion depth: Influenced by air on NiTi1 (a) and NiTi2 alloys (b), influenced by the tide on NiTi1 (c) and NiTi2 alloys (d), influenced by sea on NiTi1 (e) and NiTi2 alloys (f). 


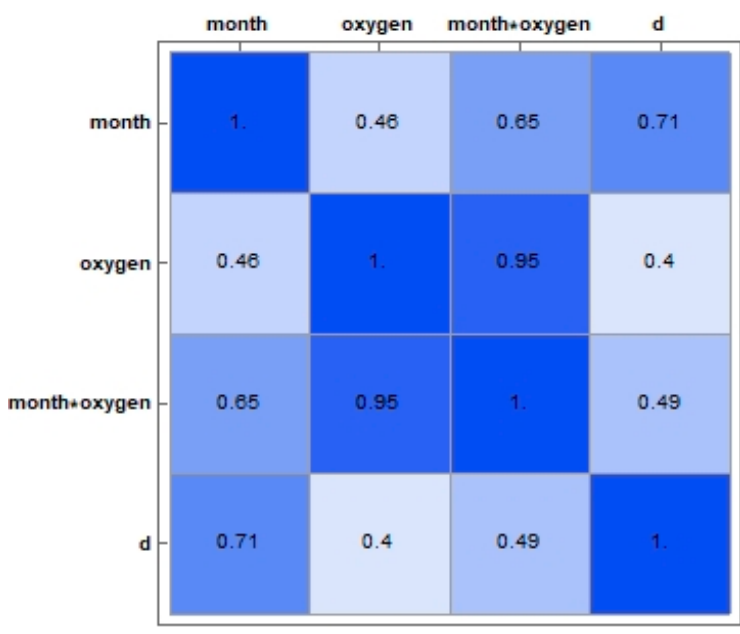

(a)

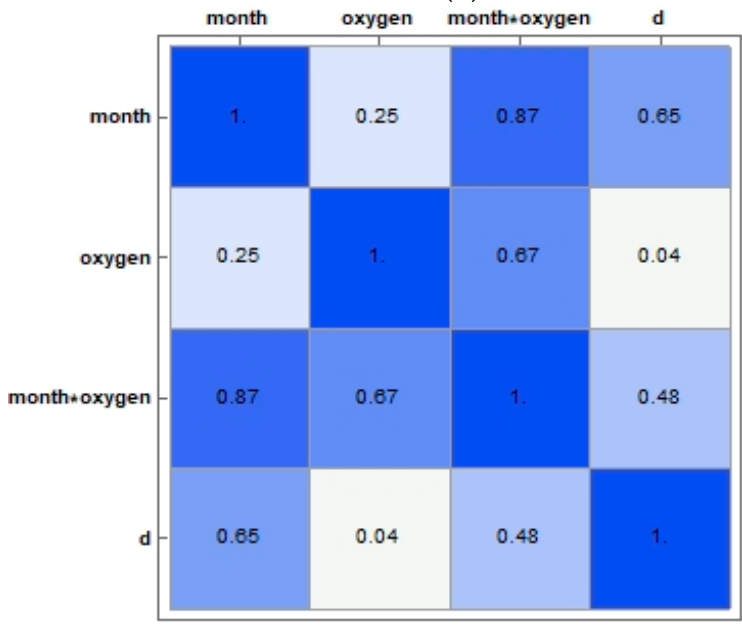

(c)

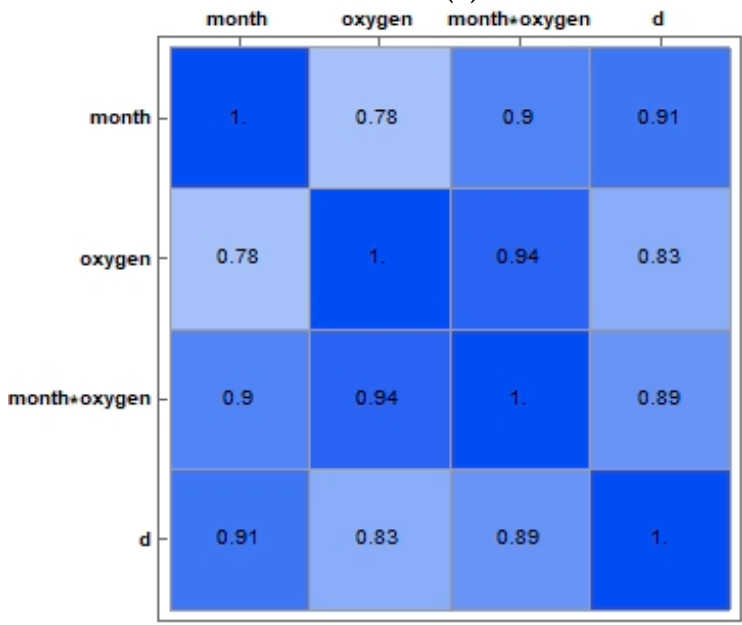

(e)

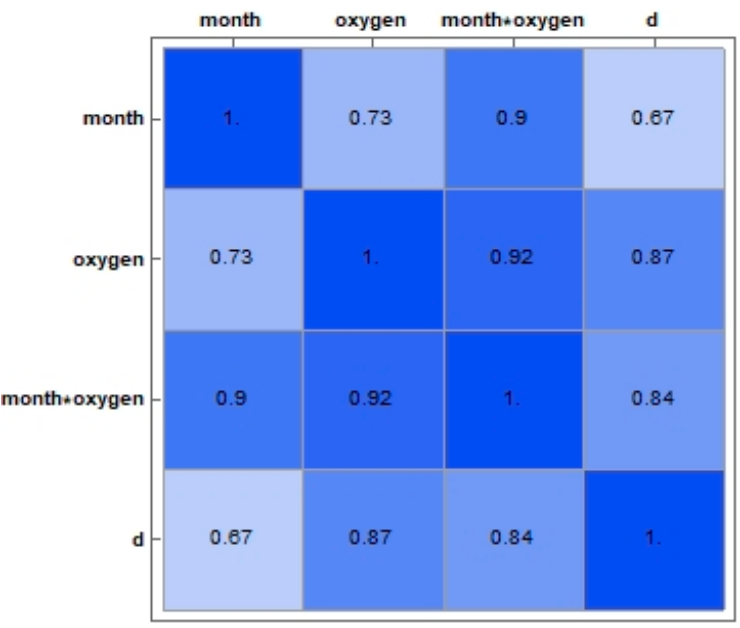

(b)

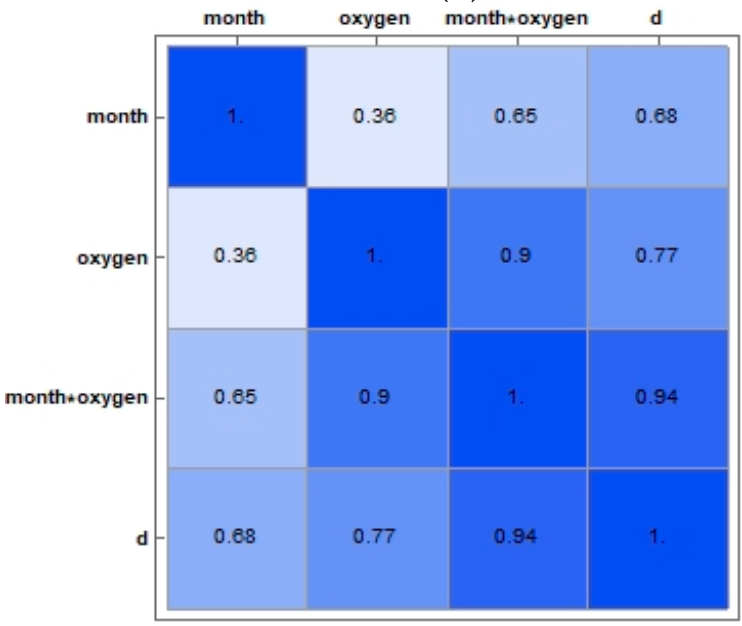

(d)

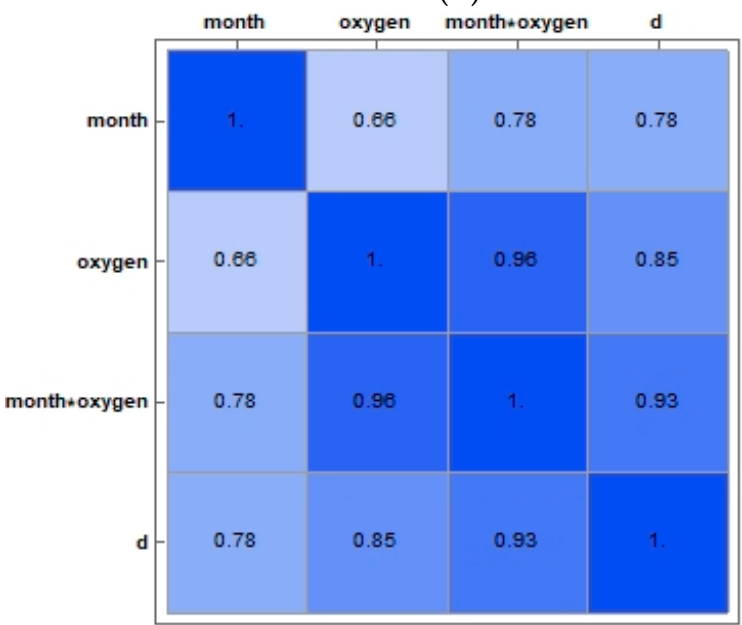

(f)

Figure 5. Correlation analysis between the predictors (oxygen percentage and exposure time) and response variable (corrosion depth): Influenced by air on NiTi1 (a) and NiTi2 alloys (b), influenced by tide on NiTi1 (c) and NiTi2 alloys (d), influenced by sea on NiTi1 (e) and NiTi2 alloys (f).

Using a generalised regression model with the form shown in Formula (1), concrete models were formed by applying it to the empirical databases. Completely new and undamaged samples were used in the experiment so the development of the model started from the initial assumption that in the zero month the corrosion depth, as well as the 
percentage of oxygen, was equal to zero for each sample subjected to the experiment. Therefore, the value of the intercept parameter $\beta_{0}$ in the regression model was also set to zero. In the modelling process, the corrosion depth was observed as a dependent quantity. The notations $d_{A}{ }^{(1)}, d_{T}(1)$, and $d_{S}{ }^{(1)}$, were introduced in order to differentiate the regression models associated with each observed alloy and the seawater environment for the NiTi1 alloy. The same notation was used for the NiTi2 alloy, and the obtained regression models were noted as notations $d_{A}{ }^{(2)}, d_{T}{ }^{(2)}$, and $d_{S}{ }^{(2)}$. The independent variables were denoted as $x_{1}, x_{2}$, and $x_{3}$, respectively, in each regression model formed. These three variables are explanatory variables which, in the presented regression models, are respectively associated with the time elapsed since the beginning of the experiment, the percentage of oxygen in the alloy, and the simultaneous interaction of oxygen and elapsed time (obtained by multiplying these two values). The coefficients of the explanatory variables in the regression models are denoted by $\beta_{1}, \beta_{2}$, and $\beta_{3}$, respectively. The results of regression analysis for the NiTi1 alloy are shown in Table 4 , while the results of the regression analysis obtained for the NiTi2 alloy are presented in Table 5.

Table 4. The regression parameters of the three formed models for NiTi1 corrosion depth in the air, tides, and sea.

\begin{tabular}{cccccc}
\hline Environment & Coefficient & Estimate & Std. Error & T-Statistics & $p$-Value \\
\hline \multirow{3}{*}{ air } & $\beta_{1}$ & 3.43 & 0.23 & 14.9993 & $6.534 \times 10^{-15}$ \\
& $\beta_{2}$ & 2.28 & 0.45 & 5.05198 & 0.0000240593 \\
& $\beta_{3}$ & -0.158 & 0.030 & -5.31239 & 0.0000118121 \\
\hline \multirow{3}{*}{ tide } & $\beta_{1}$ & 4.01 & 0.44 & 9.11348 & $4.2203 \times 10^{-11}$ \\
& $\beta_{2}$ & 0.71 & 0.12 & 5.99005 & $5.87456 \times 10^{-7}$ \\
& $\beta_{3}$ & -0.081 & 0.016 & -5.14946 & $8.31654 \times 10^{-6}$ \\
\hline \multirow{2}{*}{ sea } & $\beta_{1}$ & 12.1 & 2.5 & 4.81956 & 0.0000160634 \\
& $\beta_{2}$ & -0.2 & 1.7 & -0.126129 & 0.900179 \\
& $\beta_{3}$ & 0.347 & 0.095 & 3.64388 & 0.000680433 \\
\hline
\end{tabular}

Table 5. The regression parameters of the three formed models for NiTi2 corrosion depth in the air, tides, and sea.

\begin{tabular}{cccccc}
\hline Environment & Coefficient & Estimate & Std. Error & T-Statistics & $p$-Value \\
\hline \multirow{4}{*}{ air } & $\beta_{1}$ & 1.9 & 0.3 & 6.15705 & $2.7005 \times 10^{-8}$ \\
& $\beta_{2}$ & 2.57 & 0.21 & 12.129 & $6.71858 \times 10^{-20}$ \\
& $\beta_{3}$ & -0.072 & 0.013 & -5.36675 & $7.45103 \times 10^{-7}$ \\
\hline \multirow{3}{*}{ tide } & $\beta_{1}$ & 2.26 & 0.82 & 2.74865 & 0.00765672 \\
& $\beta_{2}$ & -1.32 & 0.37 & -3.52885 & 0.000753474 \\
& $\beta_{3}$ & 0.326 & 0.025 & 13.2707 & $1.51324 \times 10^{-20}$ \\
\hline \multirow{2}{*}{ sea } & $\beta_{1}$ & 11.3 & 1.7 & 6.7345 & $6.61253 \times 10^{-9}$ \\
& $\beta_{2}$ & -0.47 & 0.64 & -0.736475 & 0.464264 \\
& $\beta_{3}$ & 0.210 & 0.035 & 6.05822 & $9.32832 \times 10^{-8}$ \\
\hline
\end{tabular}

The significance level in this regression analysis was set to 95\%, or, more precisely, a value of 0.05 was taken as the $\alpha$ parameter. Comparing the $\alpha$ parameters and the corresponding $p$-values in Tables 4 and 5, it can be concluded that all three observed independent model variables are significant for the air and tidal environments for both observed NiTi alloys. The values of the coefficients of the independent variables are shown in the third column of Tables 4 and 5 .

For both NiTi alloys in the sea environment, it is notable that oxygen does not have a statistically significant effect on the corrosive processes. This indicates the need for further study of the corrosive regression model associated with NiTi alloys in a marine environment. It is evident that complex corrosive processes in seawater are influenced by 
many additional factors and it is necessary to perform additional analyses to determine which environmental parameters need to be included in regression models.

The resulting linear regression models describing the depth of corrosion for the NiTi1 alloy with the coefficients listed in Table 4 are shown in Formulas (2)-(4). Regression models for the corrosion depth of the NiTi1 alloy in air, tide, and sea environments, are presented respectively.

$$
\begin{aligned}
d_{A}^{(1)} & =3.43 x_{1}+2.28 x_{2}-0.158 x_{3} \\
d_{T}{ }^{(1)} & =4.01 x_{1}+0.71 x_{2}-0.081 x_{3} \\
d_{S}{ }^{(1)} & =12.1 x_{1}-0.2 x_{2}+0.347 x_{3}
\end{aligned}
$$

The regression models for the corrosion depth of the NiTi2 alloy influenced by air, tide, and sea environments are presented in Formulas (5)-(7). These models were obtained by applying the coefficient values from Table 5 in the general regression model shown in (1).

$$
\begin{aligned}
& d_{A}^{(2)}=1.9 x_{1}+2.57 x_{2}-0.072 x_{3} \\
& d_{T}^{(2)}=2.26 x_{1}-1.32 x_{2}+0.326 x_{3} \\
& d_{S}{ }^{(2)}=11.3 x_{1}-0.47 x_{2}+0.210 x_{3}
\end{aligned}
$$

The coefficient of determination, i.e., $\mathrm{R}^{2}$, was used to estimate the goodness of fit for the six regression models represented by expressions (2)-(7). The corresponding values of $\mathrm{R}^{2}$ for the three formed regression models $\left(d_{A}{ }^{(1)}, d_{T}{ }^{(1)}\right.$, and $\left.d_{S}{ }^{(1)}\right)$ equal $0.9595,0.9619$ and 0.9626 , respectively. The calculated coefficients of determination for the NiTi2 alloy and corresponding linear regression models in the three observed seawater environments $\left(d_{A}{ }^{(2)}, d_{T}{ }^{(2)}\right.$, and $\left.d_{S}{ }^{(2)}\right)$ are $0.9782,0.9544$ and 0.9556 , respectively.

As a statistical tool for hypothesis testing, analysis of variance (ANOVA) was used to check if there was a significant linear relationship [28] between the corrosion depth and the chosen explanatory variables. The obtained linear regression models (2)-(7) were verified by an ANOVA test with a 95\% confidence level. The ANOVA results for regression models (2)-(4) are summarised in Table 6. The results of hypothesis testing by ANOVA in the case of the NiTi2 alloy are shown in Table 7. Tables 6 and 7 show the Degrees of Freedom (DF), Adjusted Sums of Squares (AdjSS), and Adjusted Mean Square (AdjMS) for the regression model, error, and the total.

Table 6. The regression analysis of variance for the NiTi1 alloy samples for the three observed types of marine environment.

\begin{tabular}{ccccccc}
\hline Environment & Source & DF & AdjSS & AdjMS & F-Value & $p$-Value \\
\hline \multirow{4}{*}{ air } & Regression & 3 & $58,169.5$ & $19,389.8$ & 221.06 & 0.000 \\
& Error & 28 & 2456.0 & 87.7 & & \\
& Total & 31 & $60,625.5$ & & & \\
\hline \multirow{3}{*}{ tide } & Regression & 3 & $63,852.8$ & $21,284.3$ & 319.80 & 0.000 \\
& Error & 38 & 2529.1 & 66.6 & & \\
& Total & 41 & $66,381.9$ & & & \\
\hline \multirow{3}{*}{ sea } & Regression & 3 & $4,891,817$ & $1,630,606$ & 394.81 & 0.000 \\
& Error & 46 & 189,984 & 4130 & & \\
& Total & 49 & $5,081,800$ & & & \\
\hline
\end{tabular}

To determine whether models that do not contain explanatory variables describe empirical data better than the formed regression models [29], a statistical test known as the F-test was used. From Tables 6 and 7 it is evident that, for both observed NiTi alloys and each observed seawater environment, the formed linear regression models describe the behaviour of the alloys well from the point of view of corrosion depth. More precisely, the models represented by Formulas (2)-(7) can be used to predict future corrosion depth 
values of NiTi1 and NiTi2 alloys as well as to estimate the corrosion depth of these alloys based on the known values of the explanatory variables. This conclusion is in full agreement with the conclusion obtained when observing the previously calculated values of $R^{2}$.

Table 7. The regression analysis of variance for the NiTi2 alloy samples for the three observed types of marine environment.

\begin{tabular}{ccccccc}
\hline Environment & Source & DF & AdjSS & AdjMS & F-Value & $p$-Value \\
\hline \multirow{4}{*}{ air } & Regression & 3 & 266,918 & $88,972.8$ & 1209.61 & 0.000 \\
& Error & 81 & 5958 & 73.6 & & \\
& Total & 84 & 272,876 & & & \\
\hline \multirow{3}{*}{ tide } & Regression & 3 & $3,106,113$ & $1,035,371$ & 474.31 & 0.000 \\
& Error & 68 & 148,438 & 2183 & & \\
& Total & 71 & $3,254,551$ & & & \\
\hline \multirow{2}{*}{ sea } & Regression & 3 & $7,485,870$ & $2,495,290$ & 437.95 & 0.000 \\
& Error & 61 & 347,553 & 5698 & & \\
& Total & 64 & $7,833,424$ & & & \\
\hline
\end{tabular}

One of the techniques for examining the quality of a regression model is a graphical representation of the normal residual probability [30]. A normal residual plot is shown in Figure 6 for both observed NiTi alloys and all three marine environment types. It is noticeable that the analysed regression model describes corrosion depth adequately as the independent variable. Namely, the residual plot indicates the fact that the residuals followed the normal distribution. Therefore, it can be concluded that there were no deviations, unexpected behaviour, or evident existence of unidentified explanatory variables in the formed regression models.

A general conclusion can be drawn based on the previously described results of statistical analysis. The functional dependence of the corrosion depth as a response variable described by models (2)-(7) was determined adequately. As a consequence of this result, the formed regression models (2)-(7) can predict future values of corrosion depth as a function of the three observed explanatory variables adequately. By applying these models, it is possible to estimate the depth of corrosion if the values of all three independent variables are known. A graphical representation of the estimated values of corrosion depth depending on the type of seawater environment is shown in Figures 7-9. Each figure shows one of the three observed seawater environments. In these figures, the corrosion depth values are shown using a scale where blue shades illustrate the lowest values while red shades illustrate the highest corrosion depth values. In each of the figures, the illustration on the left refers to the NiTi1 alloy, while the illustration on the right is associated with the NiTi2 alloy. Based on the graphical representation of the estimated values of corrosion depth, there are differences between the corrosive behaviour of the observed NiTi alloys depending on their exposure to the seawater environment but also the different behaviours of the NiTi1 and NiTi2 alloys when considering the influence of the explanatory variables in the observed environment.

Since the statistical analysis indicated the fact that, under the influence of the sea environment, oxygen cannot be considered a statistically significant explanatory variable, the regression analysis for corrosion depth was repeated and, in this case, oxygen was eliminated from consideration. The results of the obtained regression analysis can be represented by the following formulas:

$$
\begin{aligned}
& d_{S}{ }^{(1)}=11.90 x_{1}+0.34 x_{3} \\
& d_{S}{ }^{(2)}=10.69 x_{1}+0.19 x_{3}
\end{aligned}
$$


The corresponding $\mathrm{R}^{2}$ values are 0.9638 and 0.9552 for the NiTi1 and NiTi2 alloy, respectively, showing that these linear models explain $96.38 \%$ and $95.52 \%$, respectively, of the corrosion depth variable variation for both alloys.

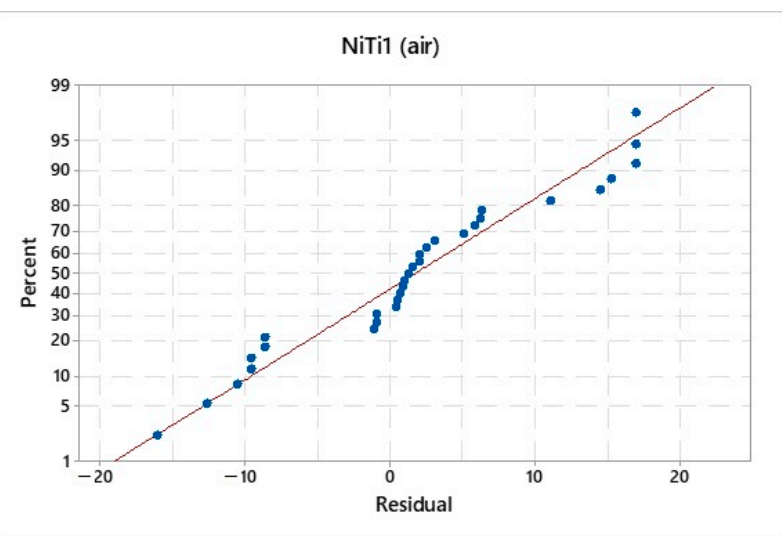

(a)

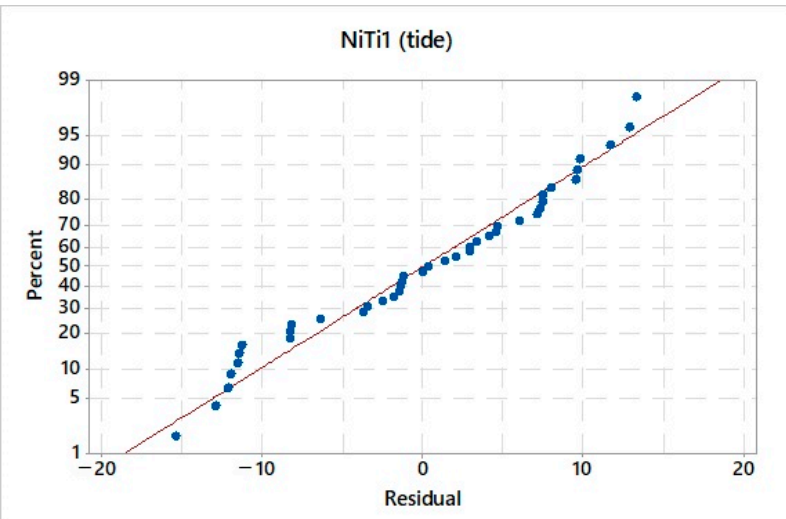

(c)

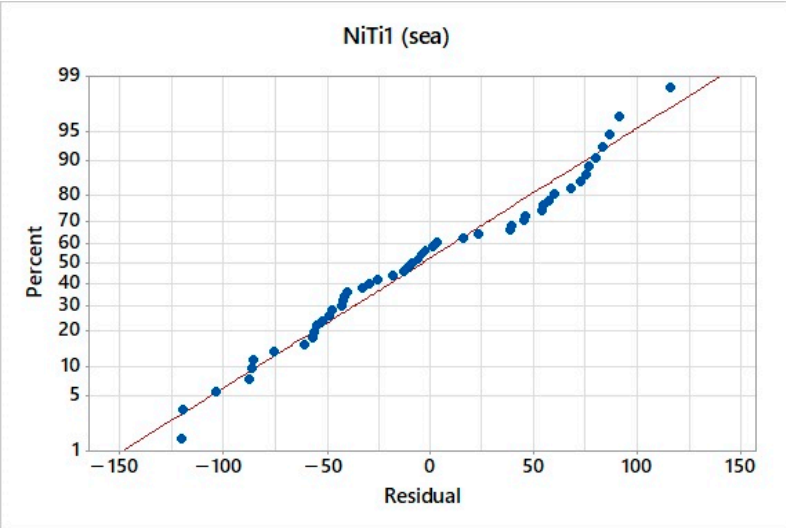

(e)

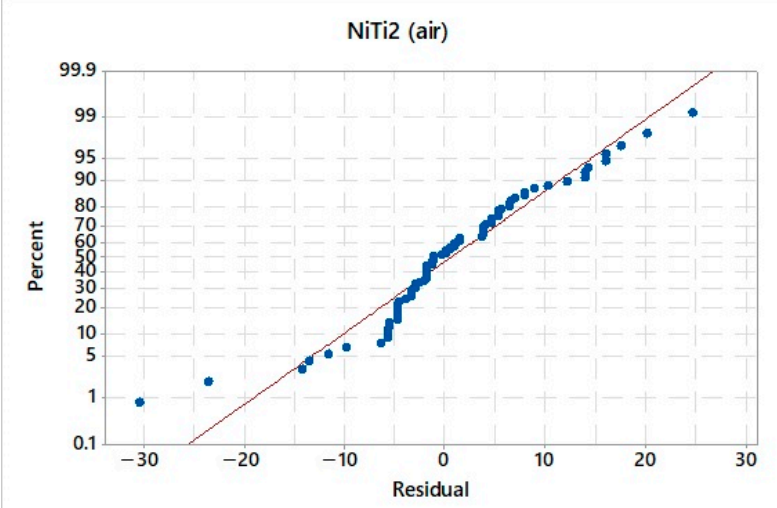

(b)

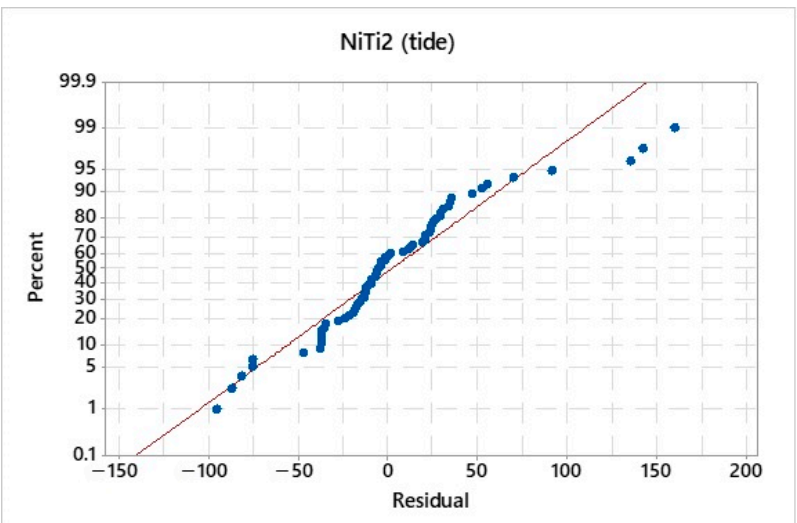

(d)

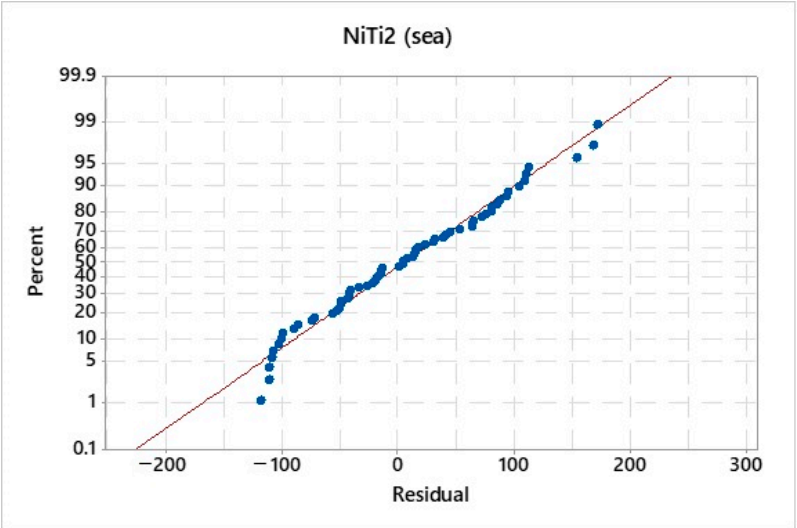

(f)

Figure 6. A normal probability plot of residuals for corrosion depth influenced by air on NiTi1 (a) and NiTi2 alloys (b), influenced by the tide on NiTi1 (c) and NiTi2 alloys (d), influenced by sea on NiTi1 (e) and NiTi2 alloys (f). 


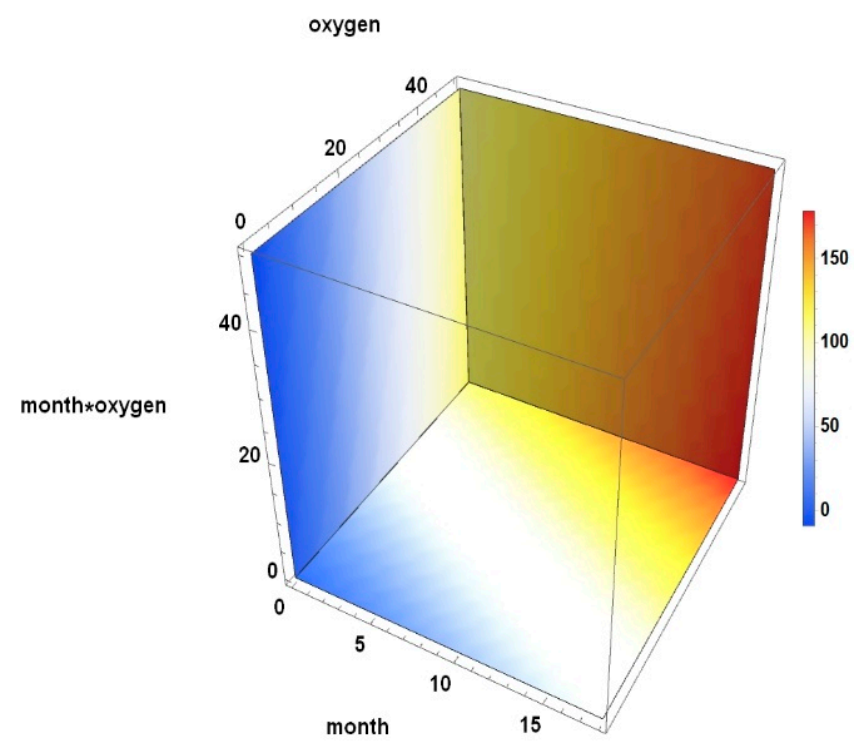

(a)
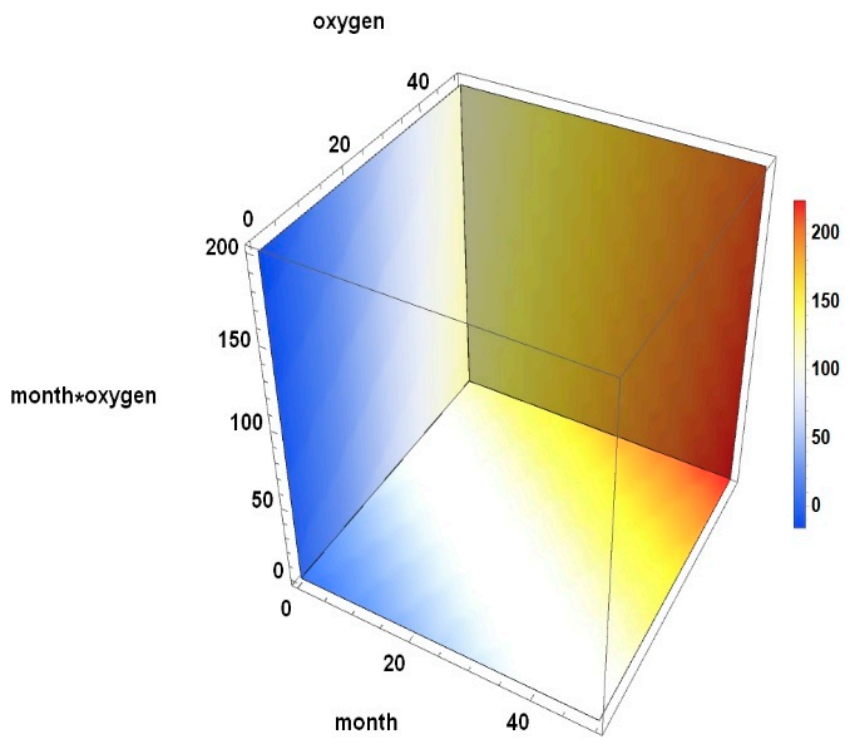

(b)

Figure 7. Predicted values of the corrosion depth obtained on the basis of regression models formed for the behaviour of the alloy under the influence of air on NiTi1 (a) and NiTi2 alloy (b).

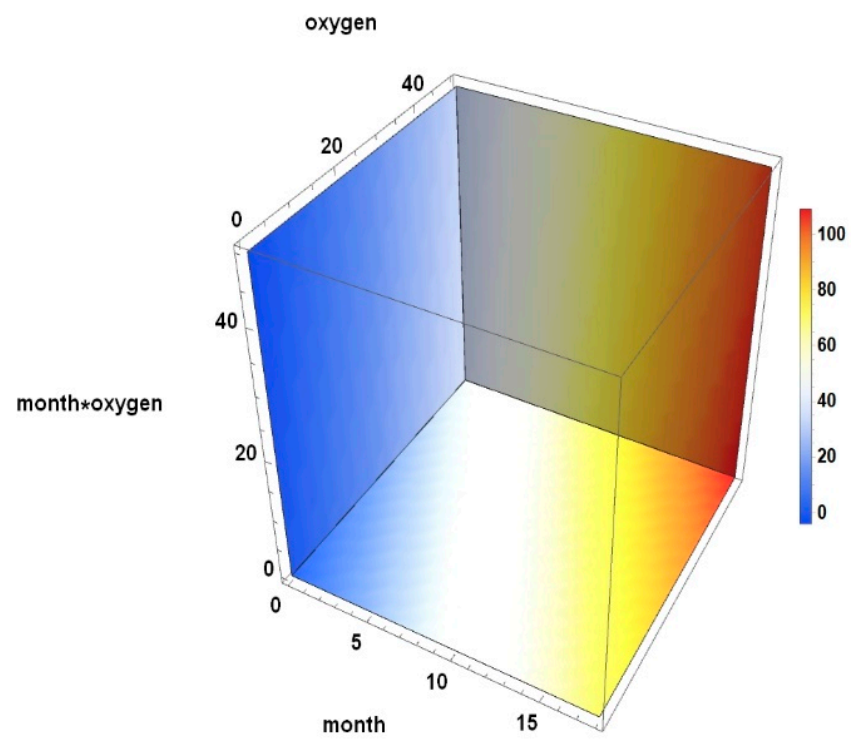

(a)

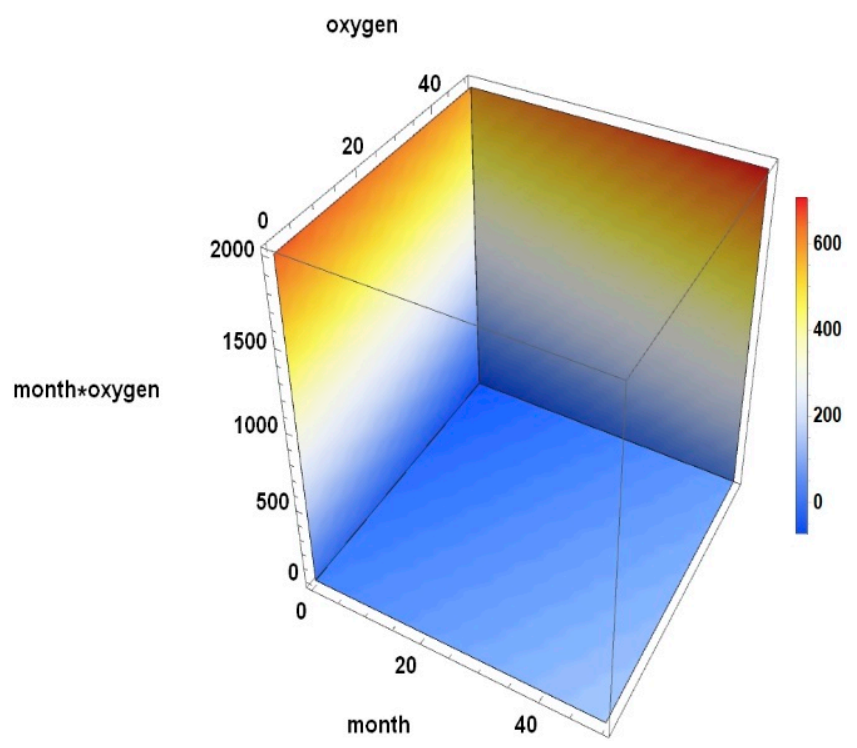

(b)

Figure 8. Predicted values of the corrosion depth obtained on the basis of regression models formed for the behaviour of the alloy under the influence of tide on NiTi1 (a) and NiTi2 alloy (b). 


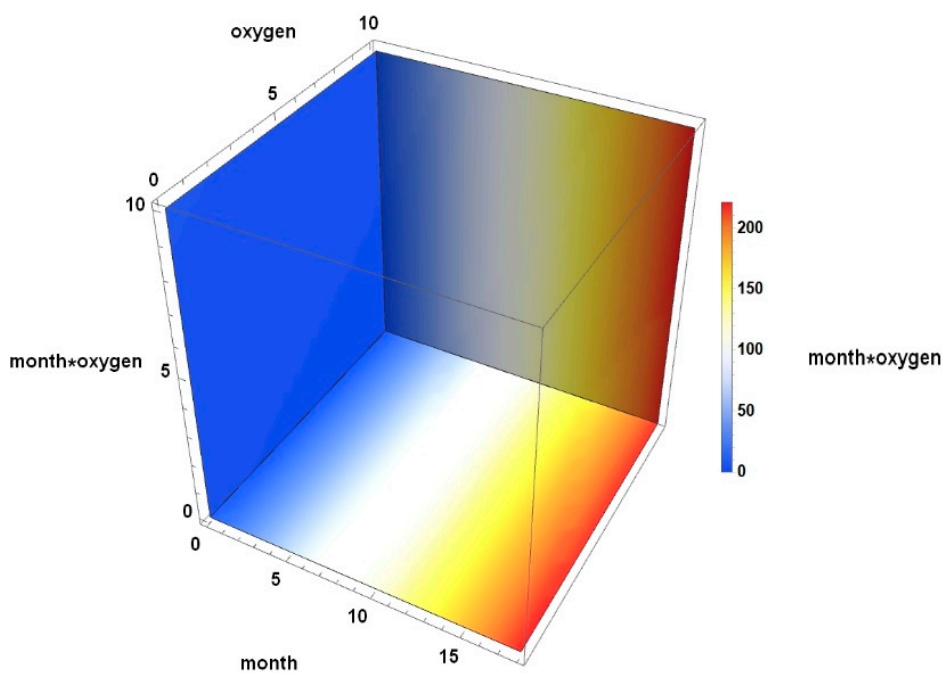

(a)

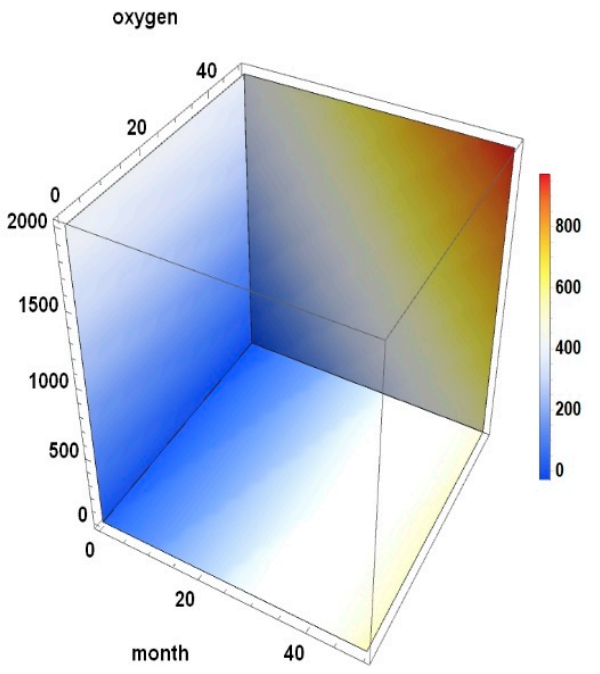

(b)

Figure 9. Predicted values of the corrosion depth obtained on the basis of regression models formed for the behaviour of the alloy under the influence of sea on NiTi1 (a) and NiTi2 alloy (b).

\section{Discussion}

The definition of the marine environment represents the interconnected body of saltwater and the coastal area. In this environment, the movement of seawater due to the gravitational force of the moon as tides, the action of winds as waves, and the changes in air pressure and temperature differences that cause sea currents, etc., are crucial. Thus, corrosion tests were performed in a real environment where the samples were affected by influences arising from the marine environment and not from simulations in the laboratory where it is not possible to create conditions that could ensure validity. The research in this paper is based on the examination of the corrosive behaviour of two different NiTi alloys (different technological production processes were applied) whose selected samples were subjected to the influence of three different seawater environments. Samples that were not treated with corrosive protective coatings and which initially did not have corrosive damage were exposed to the air, tide, and sea for 6, 12, and 18 months. Afterwards, the testing samples were subjected to SEM/FIB and EDX analysis which provided data on the resulting corrosion depth (expressed in $\mathrm{nm}$ ) and the percentage of oxygen that developed on the surface of the samples. In a continuation of the research, statistical analysis based on multivariate linear regression was applied in order to examine the functional dependence of the corrosion depth of the observed samples' surfaces on the determined percentage of oxygen, exposure time of the sample, and the simultaneous influence of these two variables. More precisely, the depth of corrosion was taken as the response variable, while the percentage of oxygen, the time of exposure to the environment (expressed in months), and the joint impact of these two variables were considered as explanatory variables. Regression analysis confirmed the assumption that the corrosion depth of both NiTi alloys can be represented adequately by the formed linear model and that the selected model parameters were statistically significant. Corrosion depth regression models of both NiTi alloys in all three seawater environments can be used to predict and estimate the future values of corrosion depth.

In the case of the NiTi1 alloy, the lowest percentage of oxygen was determined under the influence of air, slightly higher under the influence of the sea, and the highest was under the influence of the tide environment; however, the values in the tide and sea environments were approximately the same. In the case of the NiTi2 alloy, the percentage of oxygen increased progressively when the influence of air, tide, and sea was observed. The percentage of oxygen in all environments was higher on the NiTi2 alloy's surface compared to NiTi1. 
From the point of view of corrosion depth, the NiTi1 alloy surface behaved similarly in both air and tide environments, but in a sea environment, the corrosion depth was 6.49 times greater than that caused by air and 7.25 times greater than the depth of corrosion caused by the tide. In the case of the NiTi2 alloy's surface, the depth of corrosion followed the trend of increasing the percentage of oxygen and was the lowest for air, then for the tide, and the highest for the sea. However, the values of corrosion depth were three times higher in the tide environment and five times higher in the sea environment compared to the air environment. Both alloys behaved similarly from the point of view of corrosion depth in both air and sea environments, while they had significantly different behaviours in tide environments which are considered the most complex due to their constant dynamics and changes in wet and dry periods. The average corrosion depth value was four times higher for the NiTi2 alloy compared to the NiTi1 alloy's surface for the tidal environment. The resulting difference in the corrosion behaviour of the two NiTi alloys can be attributed to their different microstructures resulting from different production processes. Similar conclusions were reached by other authors in comparative studies [31,32] when they determined the functional properties of NiTi alloys depending on the production technique.

In this paper, we intended to monitor the corrosion behaviour of NiTi alloy in the marine environment over a long time period to get a more realistic picture of the impact of different marine environments on the degradation of the tested NiTi alloy. We were mostly interested in the differences in the chemical composition of the corrosion products which were precipitated on the surfaces. In this study, we wanted to determine separately in three places, the influence of all conditions of the marine environment on the corrosion process, and thus, on the resistance of a NiTi alloy. Monitoring the corrosion potential always gives very important information about corrosion processes. Therefore, the samples' connections (resulting in the galvanic cells) will be used in our future studies. Extending the defined databases with additional measurements after the prolonged influence of the seawater environment as well as adding new explanatory variables to the regression models (such as the microstructure and phase composition of NiTi alloy) represent the future directions of this research. In order to avoid possible problems caused by highly collinearly dependent model variables, an additional application of principal component analysis, or partial least squares regression, is planned.

\section{Conclusions}

Within the performed research on two types of NiTi alloys, we came to the following findings:

1. Oxygen showed a statistically significant impact on the development of corrosion processes in the air and tide environments on both NiTi alloys' surfaces which was not noticeable in the case in the sea environment.

2. Statistical analysis showed that the independent influence of oxygen percentage as a parameter of the regression model does not affect the development of NiTi alloy corrosion processes statistically significantly.

3. The joint influence of oxygen percentage and environmental exposure time is a statistically unavoidable factor for the regression analysis of corrosion depth for both NiTi alloys.

4. The formation of corrosion depth on the NiTi alloys' surfaces being dependent on the influence of the sea, points to complex processes occurring in the marine environment.

5. This study discovered the need to consider more complex models with additional environmental parameters as explanatory variables as well as the joint impact of these single variables on corrosion depth. 


\begin{abstract}
Author Contributions: Conceptualisation, N.K. and Š.I.; methodology, N.K. Š.I. and R.R.; software, N.K.; validation, G.V. and R.R.; formal analysis, P.M. and N.K.; investigation, N.K., Š.I., R.R. and P.M.; resources, Š.I. and R.R.; data curation, P.M.; writing—original draft preparation, N.K. and Š.I.; writing—review and editing, R.R.; visualisation, N.K.; supervision, Š.I. and R.R.; project administration, S.I.; and funding acquisition, Š.I. and R.R. All authors have read and agreed to the published version of the manuscript.
\end{abstract}

Funding: This research was funded by the Bilateral projects Slovenia-Montenegro (BI-ME/18-20024) and Serbia-Montenegro (01-3440/2018) and Eureka program PROCHA-SMA E!13080 funded by Ministry of Science of the Republic of Montenegro.

Institutional Review Board Statement: Not applicable.

Informed Consent Statement: Not applicable.

Data Availability Statement: Not applicable.

Acknowledgments: This paper is the result of an initial phase of the research on different influences of the sea and atmosphere on the production and application of smart materials of Shape Memory Alloys in the Maritime industry. Project PROCHA-SMA E!13080 is a part of the EUREKA project which is realised jointly by the Faculty of Dental Medicine in Belgrade, Zlatarna Celje AD Beograd, and the Faculty of Maritime Studies Kotor, the University of Montenegro.

Conflicts of Interest: The authors declare no conflict of interest.

\title{
References
}

1. Ölander, A. An electrochemical investigation of solid cadmium-gold alloys. J. Am. Chem. Soc. 1932, 54, 3819-3833. [CrossRef]

2. Jani, J.M.; Leary, M.; Subic, A.; Gibson, M.A. A review of shape memory alloy research, applications and opportunities. Mater. Des. 2014, 56, 1078-1113. [CrossRef]

3. Huang, W. Shape Memory Alloys and Their Application to Actuators for Deployable Structures; University of Cambridge Department of Engineering: Cambridge, UK, 1998.

4. Ivošević, Š.; Rudolf, R.; Kovač, D. The overview of the varied influences of the seawater and atmosphere to corrosive processes. In Proceedings of the 1st International Conference of Maritime Science \& Technology, NAŠE MORE, Dubrovnik, Croatia, 17 October 2019; pp. 17-18.

5. Buehler, W.J.; Wang, F.E. A summary of recent research on the nitinol alloys and their potential application in ocean engineering. Ocean Eng. 1968, 1, 105-120. [CrossRef]

6. Kauffman, G.B.; Mayo, I. The Story of Nitinol: The Serendipitous Discovery of the Memory Metal and Its Applications. Chem. Educ. 1997, 2, 1-21. [CrossRef]

7. San Juan, J. Applications of Shape Memory Alloys to the Transport Industry. In Proceedings of the International Congress on Innovative Solutions for the Advancement of the Transport Industry, San Sebastian, Spain, 4-6 October 2006.

8. Sharma, N.; Jangra, K.K.; Raj, T. Fabrication of NiTi alloy: A review. Proc. Inst. Mech. Eng. Part L J. Mater. Des. Appl. 2015, 232, 250-269. [CrossRef]

9. Merola, C.; Cheng, H.-W.; Schwenzfeier, K.; Kristiansen, K.; Chen, Y.-J.; Dobbs, H.A.; Israelachvili, J.N.; Valtiner, M. In situ nanoto microscopic imaging and growth mechanism of electrochemical dissolution (e.g., corrosion) of a confined metal surface. Proc. Natl. Acad. Sci. USA 2017, 114, 9541-9546. [CrossRef] [PubMed]

10. Soares, C.; Garbatov, Y. Reliability of maintained, corrosion protected plates subjected to non-linear corrosion and compressive loads. Mar. Struct. 1999, 12, 425-445. [CrossRef]

11. Yamamoto, N.; Ikegami, K. A Study on the Degradation of Coating and Corrosion of Ship's Hull Based on the Probabilistic Approach. J. Offshore Mech. Arct. Eng. 1998, 120, 121-128. [CrossRef]

12. Paik, J.K.; Kim, S.K.; Lee, S.K. Probabilistic corrosion rate estimation model for longitudinal strength members of bulk carriers. Ocean Eng. 1998, 25, 837-860. [CrossRef]

13. Paik, J.K. A time-dependent corrosion wastage model for bulk carrier structures. Int. J. Marit. Eng. R. Just Naval. Arch. 2003, 145, 61-87.

14. Paik, J.K. Corrosion Analysis of Seawater Ballast Tank Structures. Int. J. Marit. Eng. 2004, 146, 15. [CrossRef]

15. Melchers, R. Corrosion uncertainty modelling for steel structures. J. Constr. Steel Res. 1999, 52, 3-19. [CrossRef]

16. Melchers, R.E. Probabilistic Model for Marine Corrosion of Steel for Structural Reliability Assessment. J. Struct. Eng. 2003, 129, 1484-1493. [CrossRef]

17. Melchers, R.E. Factors Influencing the Immersion Corrosion of Steels in Marine Water. In Proceedings of the 14th International Corrosion Congress, Cape Town, South Africa, 26 September-1 October 1999.

18. Lojen, G.; Stambolić, A.; Šetina Batič, B.; Rudolf, R. Experimental Continuous Casting of Nitinol. Metals 2020, 10, 505. [CrossRef]

19. Stambolič, A.; Anžel, I.; Lojen, G.; Kocijan, A.; Jenko, M.; Rudolf, R. Continuous vertical casting of a NiTi alloy. Mater. Tehnol. 2016, 50, 981-988. [CrossRef] 
20. Kovač, N.; Ivošević, Š.; Vastag, G.; Vukelić, G.; Rudolf, R. Statistical Approach to the Analysis of the Corrosive Behaviour of NiTi Alloys under the Influence of Different Seawater Environments. Appl. Sci. 2021, 11, 8825. [CrossRef]

21. Kovač, N.; Ivošević, Š.; Gagić, R. Estimation of the NiTi alloy corrosion rate dependence on the percentage of oxygen in three different seawater environments. ICONST EST'21 2021, 1, 323-334.

22. Ivošević, Š.; Majerič, P.; Vukičević, M.; Rudolf, R. A Study of the Possible Use of Materials with Shape Memory Effect in Shipbuilding. J. Marit. Transp. Sci. 2020, 3, 265-277. [CrossRef]

23. Ivošević, Š.; Kovač, N.; Vastag, G.; Majerič, P.; Rudolf, R. A Probabilistic Method for Estimating the Influence of Corrosion on the CuAlNi Shape Memory Alloy in Different Marine Environments. Crystals 2021, 11, 274. [CrossRef]

24. Ivošević, Š.; Vastag, G.; Majerič, P.; Kovač, D.; Rudolf, R. Analysis of the Corrosion Resistance of Different Metal Materials Exposed to Varied Conditions of the Environment in the Bay of Kotor. In The Montenegrin Adriatic Coast. The Handbook of Environmental Chemistry; Joksimović, D., Đurović, M., Zonn, I.S., Kostianoy, A.G., Semenov, A.V., Eds.; Springer: Cham, Switzerland, 2020; Volume 110

25. Heckler, C.E. Applied Multivariate Statistical Analysis. Technometrics 2005, 47, 517. [CrossRef]

26. Willard, C.A. Statistical Methods: An Introduction to Basic Statistical Concepts and Analysis; Routledge: London, UK, 2020. [CrossRef]

27. Lee Rodgers, J.; Nicewander, W.A. Thirteen ways to look at the correlation coefficient. Am. Stat. 1988, 42, 59-66. [CrossRef]

28. Miller, R.G., Jr. Beyond ANOVA: Basics of Applied Statistics; CRC Press: Boca Raton, FL, USA, 1997.

29. Bingham, N.H.; Fry, J.M. Regression: Linear Models in Statistics; Springer Science \& Business Media: Berlin/Heidelberg, Germany, 2010.

30. Anscombe, F.J. Graphs in statistical analysis. Am. Stat. 1973, 27, 17-21.

31. Stambolić, A.; Jenko, M.; Kocijan, A.; Žužek, B.; Drobne, D.; Rudolf, R. Determination of mechanical and functional properties by continuous vertical cast NiTi rod = Določitev mehanskih in funkcionalnih lastnosti vertikalno kontinuirno lite NiTi palice. Mater Tehnol. 2018, 52, 521-527. Available online: http://mit.imt.si/Revija/izvodi/mit185/stambolic.pdf (accessed on 12 December 2021). [CrossRef]

32. Rudolf, R.; Stambolić, A.; Kocijan, A. Atomic layer deposition of a TiO2TiO2 layer on Nitinol and its corrosion resistance in a simulated body fluid. Metals 2021, 11, 659. Available online: https://www.mdpi.com/2075-4701/11/4/659 (accessed on 12 December 2021). [CrossRef] 